Encontros Bibli: revista eletrônica de biblioteconomia e ciência da informação, v. 17, n. esp.1, p.169-187, 2012. ISSN 1518-2924. DOI: 10.5007/1518-2924.2012v17nesp1p169

\title{
O USO DA INFORMAÇÃO NO ÂMBITO ACADÊMICO: O COMPORTAMENTO INFORMACIONAL DE PÓS-GRADUANDOS DA ÁREA DE EDUCAÇÃO
}

\author{
Helen de Castro Silva Casarin ${ }^{\mathrm{i}}$ \\ Etiene Siqueira de Oliveira ${ }^{\text {ii }}$
}

\begin{abstract}
Resumo: Este artigo relata parte de uma pesquisa mais ampla que teve como objetivo caracterizar o comportamento informacional dos pós-graduandos da área de Educação. Participaram da pesquisa nove alunos de mestrado e doutorado de um programa de pós-graduação em Educação de uma universidade pública paulista. Para coleta de dados, utilizou-se a técnica de grupo focal. As sessões foram observadas e gravadas e os dados registrados foram transcritos, categorizados e posteriormente analisados utilizando-se a técnica de análise de conteúdo. Foram levantados: i) Forma de identificação de recursos informacionais para pesquisa; ii) Visão da Internet como fonte de informação; iii) Utilização dos recursos e serviços da biblioteca universitária; iv)Treinamento para a utilização das bases de dados eletrônicas; v)Dificuldades para a realização da busca; vi) A influência do orientador no desenvolvimento da pesquisa; e vii) Fatores ambientais que afetam o comportamento de busca. Os principais resultados demonstraram que a identificação dos recursos informacionais ocorre, principalmente, por meio das referências bibliográficas de trabalhos da área; que há influência do orientador no comportamento de busca dos participantes. Em relação aos aspectos ambientais, verificou-se que falta de tempo para realizar as atividades de busca e o desconforto causado pelo ambiente físico das bibliotecas foram apontados como os principais fatores influenciavam negativamente o comportamento informacional do grupo estudado.
\end{abstract}

Palavras-chave: Comportamento informacional. Comportamento de busca. Pós-graduandos. Grupo focal. Educação. Ciência da Inormação.

\section{ACADEMIC USE OF INFORMATION: THE INFORMATION BEHAVIOR OF GRADUATE STUDENTS IN EDUCATION}

\begin{abstract}
This study reports part of a broader research about information behavior of graduate students in Education. The research's participants were nine masters and doctoral students from a graduate program in Education at a public university. The focus group technique was used to collect the data. The focus group sessions were observed and recorded. The recorded data were transcribed, categorized and then analyzed using the technique of content analysis. The main aspects achieved were: i) Identification's forms of information resources for research; ii) Internet as source of information; iii) Academic Library's services and resources use; iv) Training to use of electronic data base; v) Difficulties to perform the search; vi) Advisor's influence on research development; and vii) Environmental factors that affect information seeking behavior. The main results reveal that the identification of information sources occurs, mainly, through references quoted on studies of the researched area; as well as the advisors' influence in the information seeking behavior of the participants. The results, also, disclose some environmental aspects, as example, lack of time to search and discomfort caused by the libraries' environment that influenced negatively the information behavior of the studied group.
\end{abstract}

Keywords: Information behavior. Information seeking behavior. Graduate students. Focus Group. Information Science.

(c) (i) Esta obra está licenciada sob uma Licença Creative Commons

${ }^{\mathrm{i}}$ Universidade Estadual Paulista. helenc@marilia.unesp.br.

${ }^{\mathrm{ii}}$ Universidade Estadual Paulista. etiene.so@gmail.com. 


\section{INTRODUÇÃO}

O estudo do comportamento informacional é uma das áreas de investigação da Ciência da Informação que visa, de forma geral, identificar os fatores que geram a necessidade de informação; as etapas do processo de busca; os elementos que influenciam este comportamento e para que fim o usuário utiliza a informação obtida. Tais estudos têm contribuído para o desenvolvimento de uma série de serviços das bibliotecas (BARRET, 2005), pois, possibilitam a identificação das necessidades dos usuários e fornecem subsídios para o planejamento de produtos e serviços mais ajustados a sua comunidade, uma vez que as demandas aos serviços de bibliotecas não expressam na sua totalidade o que os usuários precisam. Bates (1996) afirma que a visão do bibliotecário acerca dos modos de acesso à informação e organização das bibliotecas desprovidas de uma investigação científica pode na verdade suprir de maneira superficial as reais necessidades dos usuários.

Nesse sentido, Silva e colaboradores (ALTRAN; OLIVEIRA; SILVA, 2005; GARCIA; SILVA 2005; SILVA, 2008; SILVA, 2011) vêm realizando uma trajetória investigativa que se iniciou com o estudo do comportamento informacional de pósgraduandos de programas de mestrado da área de Ciências Sociais e Humanas. Estes estudos revelaram que o comportamento informacional dos pós-graduandos participantes se restringia, principalmente, às fontes de informação indicadas por seus professores e que eles realizavam as buscas para o desenvolvimento de suas pesquisas utilizando principalmente os catálogos bibliográficos, em particular o catálogo de sua própria instituição, e buscadores da internet como o Google. Silva (2008) relata que os participantes não apresentaram mudanças em seu comportamento informacional ao longo do período em que cursaram a pós-graduação, pois a forma de busca e recuperação de informação para as suas pesquisas se manteve a mesma, tanto no ingresso dos alunos nos programas, quanto no momento em que estavam desenvolvendo suas pesquisas. Tal estudo revelou, especificamente, que os pós-graduandos da área de Educação participantes da pesquisa, apesar de terem conhecimento sobre as bases de dados pertinentes a sua área, possuíam mais dificuldades para realizar buscas em bases de dados em relação aos demais participantes que eram de outras áreas (SILVA, 2008).

Assim, dos estudos supramencionados emergiu o interesse em estudar o comportamento informacional de pós-graduandos de áreas específicas, uma vez que a natureza e as especificidades de cada área resultam na adoção de diferentes maneiras de produção e disseminação do conhecimento (MEADOWS, 1999). Conforme ressalta Calva 
Gonzalez (1999, p. 14): “[...] cualquier persona o sector de la sociedade prestam um cierto comportamento informativo al buscar la información que necesitam y que este se relaciona con su actividad laboral".

Deste modo, investigou-se o comportamento informacional de mestrandos e doutorandos da área de Educação, com os objetivos de caracterizar o comportamento informacional de pós-graduandos de programas de pós-graduação considerados de excelência no país na área de Educação, bem como identificar as variáveis que podem influenciar este comportamento. A pesquisa que gerou este artigo foi desenvolvida em duas fases: a primeira de cunho qualitativo e a segunda quantitativa. Neste relato serão apresentados os resultados referentes à primeira fase da pesquisa. A opção por investigar pós-graduandos da área de Educação se deu pelo fato de que os futuros educadores provavelmente irão influenciar de forma significativa o comportamento informacional de seus futuros alunos ou, de forma indireta, atuando como gestores de instituições educacionais, por exemplo, valorizando ou não a existência de bibliotecas, promovendo ou apoiando uma cultura de uso da biblioteca e de seus recursos e da competência informacional. Assim, explicitando a visão e o comportamento destes futuros educadores, pode-se identificar a necessidade de um trabalho mais efetivo de competência informacional nas instituições formadoras, o que refletirá na qualidade das pesquisas realizadas, bem como na atuação profissional dos mesmos.

\section{COMPORTAMENTO INFORMACIONAL}

Buscar informações para as várias atividades que desenvolvemos diariamente é um comportamento habitual. A maneira como lidamos com a informação, incluindo o modo como a buscamos (ou a evitamos) e a utilizamos, é denominada comportamento informacional. Para Ross Todd (2003), por exemplo, comportamento informacional é o estudo das interações entre os indivíduos, as várias formas de dados, informação e conhecimento que estão sob o rótulo da informação, assim como os diversos contextos no quais eles interagem. Para Wilson (2000, p. 49, tradução nossa), comportamento informacional é definido como:

[...] a totalidade do comportamento humano em relação as fontes e aos canais de informação, incluindo tanto a busca passiva quanto ativa e o uso da informação. Assim, isso inclui a comunicação face a face como os outros, bem como a recepção passiva de informação, como, por exemplo, assistir comerciais de TV sem prestar atenção às informações dadas. 
Quando a busca por informação é realizada de forma consciente, tal comportamento é denominado comportamento de busca de informação, que é particularmente voltado para os procedimentos empregados pelos indivíduos para encontrar, recuperar e acessar a informação. Segundo Wilson (2000, p.49, tradução nossa), comportamento de busca de informação: “[...] é a busca intencional por informação para satisfazer uma necessidade [...]”. Ao buscar as informações o indivíduo pode interagir com os sistemas de informação manual, como bibliotecas e jornais, assim como com os sistemas baseados em computador, como os sistemas online (WILSON, 2000), bem como com outros indivíduos. Para Case (2007), o comportamento de busca de informação caracteriza-se como o esforço consciente, que envolve uma variedade de comportamentos de um indivíduo para adquirir informação como resposta a uma necessidade ou a uma lacuna em seu conhecimento.

Pesquisas empíricas sobre comportamento informacional e comportamento de busca deram origem a vários modelos (FISHER; ERDELEZ; MAcKECHNIE, 2006) e ajudam a identificar os fatores envolvidos na busca e na forma dos indivíduos lidarem com a informação. O modelo de comportamento informacional de Wilson e Walsh (1996), elaborado a partir de pesquisas multidisciplinares elenca vários fatores (chamados por eles de variáveis intervenientes) que podem influenciar o comportamento informacional dos indivíduos. Estes fatores podem ser internos e externos aos indivíduos. Dentre os fatores internos estão, por exemplo, os aspectos afetivos, habilidades para utilizar as ferramentas de busca ou recursos informacionais; conhecimento prévio acerca do assunto e idiomas que o indivíduo domina. Entre os fatores externos estão: lugar onde o indivíduo mora; unidade de informação a qual ele tem acesso; quais tipos de fontes de informação ele utiliza e aspectos de acessibilidade da informação disponíveis (CALVA GONZÁLEZ, 2004).

\section{METODOLOGIA}

Esta fase da pesquisa apresentou, como participantes, alunos de um programa de pósgraduação em Educação vinculado a uma universidade pública paulista. De acordo com dados da Coordenação de Aperfeiçoamento de Pessoal de Nível Superior (CAPES), na última avaliação trienal (2007 - 2009) o programa alcançou nota cinco. Para compor o grupo participante desta fase da pesquisa, procurou-se abranger alunos de mestrado e doutorado que, preferencialmente, não se conheciam. O grupo ficou composto por nove pós-graduandos, 
sendo que seis eram mestrandos e três doutorandos. A idade variou entre 22 e 45 anos; quanto ao gênero, oito eram do sexo feminino e apenas um do sexo masculino. Sete participantes possuíam entre um e 21 anos de experiência profissional na área e dois indicaram não ter experiência profissional. Os participantes estavam distribuídos entre as seis linhas de pesquisa que compõem o Programa de Pós-Graduação em Educação da universidade na qual a coleta foi realizada, sendo elas: Política educacional; Gestão de sistemas educativos e unidades escolares; Ensino, aprendizagem e desenvolvimento humano; Abordagens pedagógicas do ensino de linguagens; Filosofia e história da educação no Brasil e Educação especial no Brasil. A fim de manter o nome em sigilo, os participantes da pesquisa foram identificados de P1 a P9.

A coleta de dados foi realizada por meio de aplicação do Grupo Focal, de acordo com os procedimentos indicados por Gatti (2005), a saber: convite e explicação breve dos procedimentos de registro do encontro aos participantes; realização de uma dinâmica para aquecimento do grupo, seguida da discussão do tema proposto; registro da discussão e transcrição dos dados na íntegra ${ }^{3}$. Foram realizadas duas sessões de grupo focal com intervalo de 15 dias entre elas. O tempo dedicado à realização de cada uma das sessões foi de aproximadamente 46 minutos.

As sessões seguiram um roteiro semi-estruturado, elaborado a partir do modelo de comportamento informacional de Wilson e Walsh (1996). As questões do roteiro eram utilizadas para introduzir algum aspecto não levantado nas discussões ou ainda para voltar à discussão nos momentos de dispersão do grupo.

O registro de áudio das sessões foi gravado utilizando-se um aparelho MP3. Para transcrição das sessões utilizou-se as normas de transcrição elaboradas por Marcuschi (1986). Os dados transcritos foram categorizados da seguintes maneira: i) Forma de identificação de recursos informacionais para pesquisa; ii) Visão da Internet como fonte de informação; iii) Utilização dos recursos e serviços da biblioteca universitária; iv)Treinamento para a utilização das bases de dados eletrônicas; v)Dificuldades para a realização da busca; vi) A influência do orientador no desenvolvimento da pesquisa; e vii) Fatores ambientais que afetam o comportamento de busca. Para análise dos dados utilizou-se a técnica de análise de conteúdo (BARDIN, 2010).

\footnotetext{
${ }^{3}$ Para um maior detalhamento a respeito da aplicação do grupo focal vide Silva e Oliveira (2011). 


\section{APRESENTAÇÃO E ANÁLISE DOS RESULTADOS}

Os resultados aqui apresentados foram organizados de acordo com as categorias anteriormente mencionadas.

\subsection{Forma de identificação e obtenção de recursos informacionais para pesquisa}

Durante a discussão os participantes expuseram de que forma identificavam recursos informacionais relevantes para o desenvolvimento de suas pesquisas. A forma de identificação mais utilizada por seis deles (P3, P4, P5, P6, P7 e P8) foi a consulta às referências citadas em trabalhos relevantes. Observa-se que ao se referirem às referências citadas ao final dos trabalhos consultados, os participantes utilizam o termo "bibliografias", como é comum entre aqueles que não são da área de documentação. Como ilustra o relato de P5:

/.../ fui pegando alguns autores, aí, da própria produção deles, a gente pega qual é a bibliografia deles pra poder citar e tal. Aí vai seguindo o caminho. (P5)

A utilização de referências arroladas ao final dos textos consultados como forma de identificação de recursos informacionais é denominada citation chasing. Nesse sentido, Green (2000) afirma que o sucesso deste procedimento para identificação de recursos informacionais relevantes reside na familiaridade dos pesquisadores da área de Humanidades com a literatura existente em sua área de atuação e na importância das fontes primárias para os pesquisadores da área, bem como na identificação de fontes de informação apropriadas. Esse resultado se assemelha com os estudos de Romanos de Tiratel (2000), Barrett (2005) e George et al. (2006), os quais relatam que os alunos da pós-graduação e pesquisadores da área de Humanidades utilizam as referências e notas de rodapé de artigos e livros para identificar documentos que sejam relevantes para suas pesquisas.

No que se refere à busca passiva, na qual o sujeito se envolve em situações que propiciam o encontro de informações relevantes e se mantém atento às possíveis informações que lhes chega às mãos (WILSON; WALSH, 1996), verificou-se que P3, P6, P9 gostam de explorar a biblioteca e seus serviços a fim de localizar possíveis documentos e informações relevantes que estejam disponíveis, como se pode observar no trecho a seguir:

\footnotetext{
$\mathrm{Eu}$ tenho a experiência de duas universidades /.../ E eu acho o sistema da* ((instituição de ensino superior com acervo aberto)) muito mais interessante porque, de repente, quando você tá procurando o livro, você encontra outras coisas que, às vezes, no terminal você não conseguiu, porque, a nomenclatura não é a mesma, ou você não sabe também que existe o livro/.../. (P9)
} 
$\mathrm{O}$ acervo aberto nas bibliotecas propicia a busca passiva por parte dos pós-graduandos, o que evidencia a importância do acervo aberto. Por outro lado, alguns dos participantes (P2, P4, P9) que frequentavam instituições com acervo fechado, ressaltaram que tal prática os impedia de realizar buscas pelo acervo, o que foi considerada pelos pós-graduandos participantes como fundamental para o desenvolvimento de suas pesquisa.

Quando os participantes discutiram a identificação de materiais bibliográficos por meio do contato pessoal com colegas da pós-graduação, cinco dos nove participantes (P2, P4, P5, P6 e P7) explicitaram que costumavam trocar informações e materiais bibliográficos (artigos, livros e bibliografias) com colegas, como ilustram os trechos abaixo:

\begin{abstract}
Eu tenho três colegas que estão fazendo doutorado/.../e, nós combinamos assim, que cada uma que receber um artigo virtual, tem que mandar pras outras. Qualquer trabalho que os professores fazem, texto que o professor passa a gente passa pra outras independente do interesse ou não, recebeu já passa. Mais por curiosidade, não sei nem se vão ler, eu, por exemplo, nunca li todos que já me mandaram, eu então eu só pego um ou outro que interessar, mas eu vou fazendo um ((fala rindo)) meu arquivozinho pessoal com esses textos. (P2)
\end{abstract}

São com poucas pessoas, alguns amigos, aí volta e meia a gente sabe que o outro tá fazendo, tem determinado tipo de pesquisa, você tá procurando uma coisa pra você e você acaba achando pro outro. Aí, você acaba mandando o link. Isso é comum. (P5)

Constata-se, assim, que os pós-graduandos utilizam as indicações de colegas da área como forma de identificação de recursos informacionais relevantes, bem como forma de obtenção desses recursos por meio de compartilhamento. Constata-se, também, que o uso de canais informais de informação, como o contato interpessoal, possui uma função no comportamento informacional dos pós-graduandos. Percebe-se que no caso de P2, o compartilhamento de materiais bibliográficos com os colegas da área ocorre de forma ordenada e contínua. Nota-se aí a existência da busca passiva. Já para P4, P5 e P6 o compartilhamento de informações e de materiais bibliográficos é comum, porém ocorre de forma mais esporádica com colegas da área. Sendo caracterizada como atenção passiva (WILSON; WALSH 1996), na qual o sujeito não tem como objetivo buscar informação, mas onde a aquisição da informação pode ocorrer em várias formas. Como ilustra o trecho a seguir:

Agora eu estou lendo quatro livros, /.../ um eu vi num artigo de revista, estava acho que num consultório médico, eu estava lendo, achei interessante e anotei. $\mathrm{O}$ outro foi numa palestra que eu estava assistindo, que não tem nada a ver com o doutorado, o palestrante orientou o livro, anotei. (P4) 
O uso da internet também foi abordado pelos participantes como forma de obtenção de informação. Segundo eles, a internet é uma das principais fontes de consulta, principalmente pela praticidade. Quanto ao volume de materiais disponíveis na rede, uma participante (P5) afirma ser esse um aspecto fundamental da internet para a realização de seus trabalhos acadêmicos e compara um levantamento bibliográfico realizado na biblioteca com um realizado na internet:

Para os nossos trabalhos, a internet ela é definitivamente A Ferramenta. Então acho que assim, eu teria muita dificuldade se não tivesse o aspecto da internet pra fazer meus trabalhos. Acho que todo mundo, atualmente né, porque a ida a biblioteca, ela ainda é mais limitada né?(P5)

Percebe-se que P5 acredita que a utilização dos recursos tradicionais da biblioteca promove um levantamento limitado quando comparado ao levantamento online proporcionado pelos recursos disponíveis na rede. Ele parece não ter a clareza de que vários recursos disponibilizados on-line, como o acesso a portais de revistas eletrônicas e bases de dados são serviços oferecidos por bibliotecas.

\subsection{Visão da internet como fonte de informação.}

Durante as discussões, alguns participantes (P1, P2, P3, P5, P8) apontaram as razões que explicam a sua opção pelas fontes disponibilizadas na internet para realização de suas pesquisas. A partir dessa categoria, foi possível perceber alguns motivos para a escolha das fontes de informação disponíveis na internet, tais como rapidez, facilidade de uso, grande volume e atualidade dos materiais disponíveis na rede.

O uso de sites de busca para a realização de levantamento bibliográfico foi mencionado por alguns participantes $(\mathrm{P} 2, \mathrm{P} 3, \mathrm{P} 8)$ devido à rapidez e facilidade de uso. Uma participante (P2) afirma que utiliza o Google intensamente, bem como seus recursos, como as aspas, o "e" comercial, para restringir seus resultados. Porém, P2 menciona um ponto importante ao afirmar que é preciso tomar cuidado com relação à confiabilidade da informação recuperada:

/.../ a única coisa que a gente sempre tem que tomar mais cuidado é a confiabilidade do que encontra, por conta disso a gente vai direto na questão de teses acadêmicas, então eu procuro /.../mesmo em teses, em dissertações, /.../ já vou direto lá no acadêmico. 
Pode-se perceber que por causa da confiabilidade das fontes de informação, P2 utiliza o Google Acadêmico, que disponibiliza prioritariamente documentos acadêmicos. A questão da atualidade também é um motivo para a escolha das fontes disponibilizadas na internet, como elucida o trecho a seguir:

A gente encontra coisa muito mais atual nesses artigos de revistas eletrônicas. Alguns momentos /.../com uma agilidade e rapidez impressionante até, né? (P1)

Embora o Google seja um dos recursos mais mencionados pelos participantes, alguns citaram o uso de revistas eletrônicas, sendo que a relevância da busca em revistas especializadas e bibliotecas eletrônicas como o Scielo foi ressaltada apenas por um participante (P7). Como ilustra o trecho a seguir:

[...] no Scielo eu peguei vários artigos. Mas em compensação eu tenho preconceito com relação à internet. (P7)

Este resultado se assemelha com o apontado no estudo de Bass et al (2008), o qual relata que $75 \%$ dos pesquisadores da área de Humanidades participantes da pesquisa apresentam um comportamento informacional inesperado ao utilizar motores de busca, como por exemplo, o Google acadêmico.

\subsection{Dificuldades para a realização da busca}

Quando os pós-graduandos discutiram a realização de levantamentos bibliográficos para o desenvolvimento de suas pesquisas, pode-se observar que alguns possuíam dificuldades para a realização de suas buscas, no que se refere ao uso de fontes de informação especializadas e mecanismos para a busca. Alguns participantes (P5, P6, P8) indicaram que essas dificuldades têm sido sentidas por eles desde a graduação, devido à falta de treinamento adequado para o uso das fontes disponíveis na biblioteca. Como ilustram os trechos a seguir:

[...] eu não tinha conhecimento disso aqui ((falando do folheto da biblioteca sobre bases de dados e catálogos online)), acho que quando eu entrei primeiro da graduação, eles não faziam esse tipo de trabalho. (P6)

[...] eu não tinha esse papelzinho ((falando do folheto da biblioteca sobre bases de dados e catálogos online)), não, foi tentativa e erro/.../ a gente vai dando tanta cabeçada, depois, na hora que descobre as coisas, fala: - Nossa, era tão simples, fica tudo mais claro agora! Mas assim, a gente tem bastante autonomia pra ir atrás das coisas e vai meio sozinho $[\ldots]$ (P5) 
Diante do exposto, pode-se supor que a maioria dos pós-graduandos não foi orientada quanto ao uso das bases de dados, isto é, a maior parte não recebeu orientações técnicas quanto ao uso das bases de dados. O estudo de Fidzani (1998) a respeito das necessidades de informação e do comportamento de busca de pós-graduandos indicou que, de maneira geral, os pós-graduandos não tinham treinamento adequado quanto ao uso dos recursos da biblioteca, bem como necessitavam de tais instruções a fim de realizar buscas mais eficientes e efetivas. A importância deste conhecimento específico acerca da utilização das bases de dados para a obtenção de bons resultados na busca indica a necessidade de um serviço mais estruturado e sistematizado de orientação para o uso da biblioteca.

\subsection{Utilização dos recursos e serviços da biblioteca universitária}

Durante as discussões, a maioria dos participantes (P1, P2, P3, P4, P5, P6 e P7) explicitou utilizar diversos recursos e serviços da biblioteca universitária para o desenvolvimento de suas pesquisas. O uso do catálogo das bibliotecas, por exemplo, foi abordado pelos participantes:

/.../você chega, no próprio computador você localiza, sabe a estante, sabe onde está. (P2)

/.../na nossa própria casa a gente já faz a pesquisa e já chega na biblioteca direcionado (para ir para o acervo). (P1)

A dificuldade do uso do catálogo, principalmente quando a instituição possui acervo fechado, foi apontada por um dos participantes:

/.../ às vezes no terminal você não conseguiu porque, a nomenclatura não é a mesma, ou você não sabe também que existe o livro /.../ Esse contato com o livro ele é fundamental. (P9)

$\mathrm{Na}$ discussão também foi levantada a necessidade de uma orientação para o uso da biblioteca e seus recursos:

Então eu acho que quando a gente chega à universidade, eu acho que seria importante a gente, lá no primeiro semestre mesmo da graduação, a gente ter uma disciplina com uma bibliotecária e ter esse direcionamento /.../ acho que iria contribuir muito. (P7)

A fala do participante P7 ressalta a necessidade de um trabalho sistematizado da biblioteca para abordar a questão da busca e uso da informação e dos recursos oferecidos pela biblioteca, o que aponta para um trabalho de competência informacional, algo que ainda não 
vem sendo suficientemente trabalhado nas bibliotecas universitárias da maioria das instituições brasileiras.

Percebe-se que os recursos e serviços utilizados pelos pós-graduandos se dividem em duas categorias: os recursos e serviços digitais (bases de dados, bibliotecas digitais e periódicos eletrônicos) e os recursos e serviços tradicionais (serviço de referência, empréstimo entre bibliotecas e acervo físico). Como ilustram os relatos a seguir:

/.../eu também já consultei a bibliotecária de referência particularmente/.../ algumas dúvidas, assim, eu vou lá na biblioteca, mas é mais pra tirar dúvidas/.../ tem muito material ai, tem, muitos livros. (P3)

/.../até pra buscar o artigo na biblioteca a gente acaba usando a internet, às vezes, na nossa própria casa a gente já faz a pesquisa e já chega na biblioteca direcionado (pra ir pro acervo) já (sai pra pegar)/.../. (P1)

/.../já vou direto nas bibliotecas das universidades, bibliotecas virtuais das universidades brasileiras e estrangeiras, e geralmente fico ali mesmo. (P2)

Observa-se que os pós-graduandos participantes desta fase da pesquisa utilizavam a biblioteca universitária de forma expressiva para o desenvolvimento de suas pesquisas acadêmicas, embora o uso de recursos eletrônicos que não são oferecidos pelas bibliotecas também se faz bastante presente. Foi possível também identificar formas incomuns de uso da biblioteca:

/.../ na verdade acho que deve ter uns cinco anos ou mais que eu NÃO entro numa biblioteca. Isso pode parecer estranho /.../ Então assim, eu quis dizer que eu não tenho contato com o bibliotecário há tanto tempo /.../ pela facilidade de pegar os livros, de acesso aos livros pela própria internet. (P2)

No caso desta participante, a biblioteca da instituição a qual ela está vinculada oferece um serviço de entrega de materiais de empréstimo aos docentes. $\mathrm{O}$ usuário faz a solicitação on-line e um funcionário entrega na sala ou departamento do docente, como ilustra o trecho a seguir:

/.../ na verdade você cria distância da biblioteca Fisicamente. Então a gente entra lá, solicita o livro e o livro é entregue. (P2)

Este resultado se assemelha aos resultados obtidos nos estudos de Calva González (1999) e Romanos de Tiratel (2000) acerca do comportamento informacional de pósgraduandos e pesquisadores da área de Humanidades. Tais estudos confirmam que a biblioteca é uma fonte de informação prioritária para os pesquisadores da área de Humanidades. P7 relaciona o uso dos recursos e serviços da biblioteca com uso de fontes confiáveis para a pesquisa, como ilustra o relato a seguir: 
Ainda eu percebo que eu posso fazer pesquisa e tudo lá em casa/.../mas não adianta eu preciso deste contato pra ter uma noção mais/.../ se eu tiver esse contato com o bibliotecário, um contato com a biblioteca /.../ assim, eu posso dizer que eu fiz um levantamento bibliográfico assim, pelo menos, é seguro. (P7)

Para P5 a experiência advinda com o desenvolvimento da pesquisa acadêmica durante o mestrado teve como resultado a percepção da importância do uso de fontes de informação confiáveis para a realização de um levantamento bibliográfico:

É interessante pra mim, porque /.../ vai dando tanta cabeçada, que depois, na hora que descobre as coisas, fala: - Nossa, era tão simples, fica tudo mais claro agora!/.../ Aí, eu acho que quando você chega no mestrado, aí é que você consegue focalizar mais as suas buscas aonde é mais, assim, em termos acadêmicos, uma coisa mais, não sei esquematizada, uma coisa mais confiável tal que outros sites, artigos tal, que a gente costumava percorrer, e na verdade faz bem para os resultados. (P5)

Assim, percebe-se que o nível de formação e a experiência com a realização de pesquisas podem influenciar no comportamento informacional dos pós-graduandos.

Um aspecto importante abordado nas discussões do grupo diz respeito à utilização dos recursos digitais da biblioteca, que são os mais utilizados pelos pós-graduandos participantes (P1, P2, P3, P5, P7). O uso efetivo de recursos digitais advém da ampla disponibilização de recursos informacionais em meio digital por parte das bibliotecas universitárias. Este resultado se assemelha com o estudo de George et al.(2006), o qual explicita que os pósgraduandos utilizavam amplamente os recursos e serviços on-line da biblioteca universitária.

Outro aspecto relevante, embora mencionado somente por $\mathrm{P} 4$, diz respeito à preferência pelo empréstimo de livros da biblioteca ao invés do uso de fotocópias de obras usadas em suas pesquisas. Sabe-se que há um amplo uso de fotocópias como opção de acesso aos recursos informacionais para o desenvolvimento de pesquisas na universidade, embora tal alternativa não seja a mais apropriada e invariavelmente fere a Lei n. 9.610 (BRASIL, 1998) que regula os Direitos Autorais. Corrêa (2004), por exemplo, afirma que o processo de reprodução dos textos acaba por imprimir-lhes uma série de mutações, que pode provocar uma leitura e interpretação equivocadas. Além disso, a mudança de suporte do texto implica na alteração das condições de transmissão e recepção pensadas originalmente por escritores e organizadores. Assim, o fato dos participantes preferirem o empréstimo entre bibliotecas à realização de cópias dos documentos é um aspecto bastante positivo. 


\subsection{Treinamento para a utilização das bases de dados eletrônicas}

Referente ao treinamento para a utilização das bases de dados, apenas duas participantes (P3, P7) afirmaram ter recebido instruções da biblioteca sobre o uso das bases de dados eletrônicas, bem como um folheto explicativo. Como explicita P3, por exemplo, no trecho a seguir:

Eu tenho esse papelzinho [folder], eu tinha até na minha carteira antes. Porque na primeira semana, quando, a gente, quando eu ingressei na graduação, é tem uma semana para os calouros /.../ Daí, ela [a bibliotecária] foi lá e explicou como usar e entregou essa (folhinha). (P3)

O "papelzinho" mencionado pelo participante era um folder preparado pela biblioteca de sua instituição, que traz informações das fontes de informação disponíveis na internet, catálogos on-line de outras bibliotecas e serviços oferecidos pela biblioteca. Este documento era bastante valorizado pelo participante que o guardava em sua carteira para que pudesse utilizá-lo quando necessário.

Alguns participantes ressaltaram, por outro lado, que a instrução recebida não foi suficiente, pois, em geral, essas orientações eram ministradas em apenas um dia e logo no início dos cursos. Mencionaram também a necessidade de um apoio para a realização de levantamentos bibliográficos. Neste caso, percebe-se que o participante desconhecia o serviço de referência de sua instituição que oferece este tipo de serviço. Demonstra por outro lado, que a biblioteca não tem conseguido divulgar de forma eficiente seus serviços mesmo entre os pós-graduandos.

A maioria dos pós-graduandos participantes desta fase da pesquisa não foi orientada quanto ao uso das bases de dados. Um dos participantes que afirmaram não ter recebido treinamento declarou que realizou seus levantamentos através de tentativa e erro, o que consumiu bastante tempo (P5).

\subsection{A influência do orientador no desenvolvimento da pesquisa}

Durante as discussões, os participantes expuseram o papel do orientador no desenvolvimento de suas pesquisas acadêmicas. Os pós-graduandos descreveram que os orientadores realizam recomendações/indicações quanto ao levantamento bibliográfico; quanto à atualidade das fontes de informação, bem como quanto às indicações das fontes de informação mais relevantes para o desenvolvimento das pesquisas. Quanto às recomendações 
acerca dos procedimentos do levantamento bibliográfico, observou-se que os orientadores de P2 e P3 recomendaram o emprego de palavras-chave, e a realização da busca considerando uma metodologia específica (estado da arte), respectivamente, como ilustram os relatos de P2 e P3:

\begin{abstract}
Bom, eu estou com os contatos iniciais ainda com o orientador ((do doutorado)), então eu não sei realmente ainda qual será a prática. Então por isso, relato minha experiência do mestrado. E no mestrado, o que aconteceu foi que minha professora, ela me orientou em relação/.../a algumas palavras-chave, e me pediu que eu fizesse todo o levantamento na biblioteca e trouxesse para ela, dali é que ela iria me ajudar a analisar/.../ Ela não sugeriu assim de cara nenhum livro não, ela falou assim: procure este, este, este, essas palavras-chave, e o que você levantar você traz para $\operatorname{mim} .(\mathrm{P} 2)$
\end{abstract}

Ah, minha pesquisa foi um estadinho da arte, como TCC /.../ ela tinha uma lista de autores, de sites de busca, sites de faculdade que eu deveria consultar. A gente, eu e ela sentamos e ampliamos um pouco, porque as coisas vão renovando, né? /.../aí, se ela achava que faltava alguma bibliografia, que ela já tinha lido, e que eu não tinha localizado, ela falava para eu incluir /.../(P3)

Constatou-se que a experiência de P2 no que se refere às recomendações do orientador de seu mestrado quanto aos procedimentos do levantamento bibliográfico está relacionada com a busca em materiais impressos. Já as recomendações de P3 estão relacionadas a buscas em sistemas automatizados. Pode-se supor que os orientadores estão modificando o tipo de recomendação sobre os procedimentos do levantamento bibliográfico devido à crescente ampliação do uso da internet e da disponibilidade de fontes de informação especializadas eletrônicas, apesar da predominância das fontes de informação impressas para a área de Humanidades (ROMANOS DE TIRATEL, 2000).

Quanto às recomendações dos orientadores no que se refere à atualidade das fontes de informação, P1 e P7 afirmaram que seus orientadores ressaltavam a importância de se observar este aspecto nas fontes de informação a serem utilizadas, conforme retrata o trecho a seguir:

/.../ ela só falava assim: - tem tal autora, tal livro, né? Esse autor, ele já contribuiu muito mas agora ele já tá meio que... sabe, você pode utilizar uns mais recentes. Mas assim, ela me deu muita liberdade agora no mestrado, e eu já to pra entregar já levantamento pra ela/.../. (P7)

No que diz respeito às indicações dos orientadores quanto às fontes de informação a serem utilizadas no levantamento bibliográfico, alguns participantes (P1, P5, P7, P8) citaram que os orientadores indicavam materiais a serem consultados/utilizados para o 
desenvolvimento de suas pesquisas, tais como: bibliotecas digitais, teses e dissertação. Como retrata o relato a seguir:

/.../ a minha orientadora do mestrado, também sempre tá falando: você pesquisou? No banco do Scielo, você pesquisou? E outros sites como o Domínio Público /.../E, enfim, é isso o que eles preconizam né? Buscar se atualizar, sempre esteja antenado, até porque meu tema também é muito recente. (P1)

Nota-se que as recomendações quanto às fontes de informação mais relevantes a serem utilizadas no levantamento bibliográfico são relacionadas essencialmente as fontes de informação formais. Constata-se, desta forma, a influência do orientador no comportamento informacional dos pós-graduandos, já que este possui um papel importante no sentido de auxiliar todo o processo de busca e recuperação da informação para a construção da pesquisa. Este resultado se assemelha com o resultado apontado por George et al. (2006), o qual revela que as instruções do orientador são, frequentemente, o primeiro passo no processo de busca. Já Barrett (2005) revela que pós-graduandos podem depender substancialmente da orientação de seus orientadores a fim de obter uma direção mais clara para a pesquisa.

\subsection{Fatores ambientais que afetam o comportamento de busca}

Durante as discussões, observou-se que há alguns fatores ambientais que influenciam o comportamento informacional dos pós-graduandos, pois eles, de forma geral, expuseram elementos do ambiente que influenciam seu comportamento de busca, sendo eles: a infraestrutura do campus universitário; o acesso livre ao acervo da biblioteca; a sensação de desconforto na biblioteca; e falta de tempo para realizar a busca. É importante ressaltar que fatores ambientais podem influenciar o comportamento de busca dos pós-graduandos tanto de maneira positiva, quanto negativa.

No que se refere aos fatores ambientais que influenciavam positivamente o comportamento de busca dos pós-graduandos (P1, P3, P6, P7, P9), verificou-se que eles estavam relacionados ao contexto dos alunos, ou seja, a universidade, como macro-ambiente diretamente relacionado a tais indivíduos, afetava positivamente a busca e uso da informação. Sendo que os elementos elencados foram: a infra-estrutura do campus (disponibilização de bons equipamentos com acesso a Internet), que permite a busca e uso de fontes de informação disponíveis na Internet, conforme a necessidade do pós-graduando; e a política de acesso livre 
ao acervo da biblioteca, o que possibilita ao pós-graduando a forma de busca passiva já mencionada anteriormente. Como elucida o relato a seguir:

/.../ eu, por exemplo, aqui ((falando da universidade)) tenho mais acesso a internet do que minha própria casa /.../do final de 2008 pra cá a gente viu como os pólos estão muito melhor equipados, a gente realmente tá recorrendo muito, eu, por exemplo, a esses acessos da internet, até algumas vezes até mais do que buscar o artigo na própria biblioteca /.../. (P1)

No que se refere aos fatores ambientais que influenciavam negativamente o comportamento de busca dos pós-graduandos (P1, P2, P4, P5 P6), observou-se que eles estavam relacionados aos fatores que compõem a situação no momento exato da atividade de busca, tais como: falta de tempo para realizar as atividades de busca; e a sensação de desconforto durante a permanência na biblioteca, devido a suas características. É importante ressaltar que a variável ambiental "falta de tempo" pode estar relacionada ao fato do aluno não residir na cidade onde está situada a instituição, na qual ele está vinculado. P1, P2, P4, por exemplo, não moram na cidade onde realizam o curso de pós-graduação e por isso não possuem tempo de freqüentar a biblioteca e utilizar seus recursos e serviços, como ilustra o trecho a seguir:

/.../ achei interessante essa colocação de marcar horário com a bibliotecária para a gente, não é? Mas como a gente está sempre de longe, só vem fazer a disciplina e volta, só vem fazer tal coisa na cidade e volta; a gente acaba não tendo tempo para esse contato. (P4)

O ambiente físico da biblioteca também pode influenciar o uso da biblioteca. Uma das participantes, por exemplo, faz o seguinte depoimento:

Ela [referindo-se a sua filha que a acompanhava] morreu de medo do espaço da biblioteca. Era um espaço aterrorizante para adolescente ((ri)), entendeu?/.../ E, aí depois que eu comecei a perceber, realmente não era um espaço agradável de estar, não é?Ao passo que uma livraria é um espaço muito gostoso, não é?(P4)

Os fatores ambientais podem afetar negativamente o comportamento informacional do usuário e tem como consequência a inibição do uso da informação. Conforme Wilson e Walsh (1996), as variáveis ambientais abrangem elementos do contexto do usuário que representam barreiras para a continuidade da atividade de busca de informação. 


\section{CONSIDERAÇÕES FINAIS}

Estudos sobre a temática de comportamento informacional têm sido realizados a fim de investigar o usuário no que se refere à busca e uso da informação. Assim, os resultados obtidos em tais estudos podem agir como subsídios para a eliminação de barreiras no uso de produtos e serviços de informação moldados de acordo com as características dos usuários, visto que a abordagem alternativa da área de Ciência da Informação, que norteia os estudos de comportamento informacional, visa satisfazer as necessidades de informação dos usuários.

Os resultados levantados neste estudo indicam que os pós-graduandos possuem certa autonomia na identificação e busca de fontes de informação, pois recorrem ao orientador e aos colegas, bem como utilizam referências de textos importantes.

Observou-se que a ação do orientador influencia de forma expressiva o comportamento de busca dos pós-graduandos, pois os alunos se baseiam, principalmente, nas recomendações dos orientadores quanto à relevância das fontes de informação a serem utilizadas, e quanto aos procedimentos para a realização do levantamento bibliográfico.

Verificou-se, ainda, que há variáveis ambientais que podem afetar tanto positiva quanto negativamente o comportamento informacional dos pós-graduandos. Foi possível notar também que os participantes têm expectativas quanto a uma ação mais efetiva da biblioteca no sentido de habilitá-los para o uso de seus recursos e realização de pesquisas bibliográficas, ao que poderia ser adicionada a elaboração de trabalhos científicos, aplicação de normas de documentação referentes a trabalhos acadêmicos, entre outros.

\section{AGRADECIMENTOS:}

Agradecemos ao CNPq o auxílio recebido para o desenvolvimento da pesquisa (CNPq 309825/2009-1).

\section{REFERÊNCIAS}

ALTRAN, P., SILVA, H. C.; OLIVEIRA, E. F. T.; Fontes de informação citadas pelos alunos de pós-graduação da UNESP de Marília (1999-2004). In: SIMPÓSIO DE FILOSOFIA E 
CIÊNCIAS DA UNESP MARÍlIA, 6., Marília, 4 - 7 out. 2005. Anais... Marília: FFC UNESP Marília; Comissão Permanente de Publicações, 2005. CD-Rom.

BARDIN, Laurence. Análise de conteúdo. Lisboa: Edições 70, 2010.

BARRETT, A. The Information-Seeking Habits of Graduate Student Researchers in the Humanities. Journal of Academic Librarianship, v. 31, n. 4, p. 324-331, jul. 2005.

BASS, A. et al. The Information Behavior of Scholars in the Humanities and Social Sciences. Washington: University of Washington, 2005.

BATES, M. J. Learning about the information seeking of interdisciplinary scholars and students. Library Trends, v. 45, n. 2, p. 155-64, Fall 1996.

BRASIL. Lei ${ }^{\circ}$ 9.610, de 19 de fevereiro de 1998. Altera, atualiza e consolida a legislação sobre direitos autorais e dá outras providências. Diário Oficial [da República Federativa do Brasil], Brasília, DF, 20 fev. 1998.

CALVA GONZÁLEZ, Juan José. O comportamiento en la búsqueda de información de los investigadores del área de humanidades y ciencias sociales. Investigación bibliotecológica, v. 13, n. 27, p. 11-40, jul./dic. 1999.

CALVA GONZÁLEZ, J. J. Las necesidades de información: fundamentos teóricos y métodos. México: Universidad Nacional Autónoma de México, 2004. 272p.

CASE, D. O. Looking for information: a survey of research on information seeking, needs, and behavior. 2. ed. Oxford: Elsevier, 2007. 350p.

CORRÊA, C. H. A. Leitura no plural: leitores entre o livro e a Xerox. Leitura: teoria e prática, v.22, n.42, p.33-40, 2004.

FIDZANI, B. T. Information needs and information-seeking behaviour of graduate students at the University of Botswana. Library Review, v. 47, n. 7, p. 329-340, 1998.

FISHER, Karen E.; ERDELEZ, Sandra; MAcKECHNIE, Lynne. Theories of information behavior. Medford : Information today, 2006. (ASIST Monograph series)

GARCIA, R. M.; SILVA, Helen de C. O comportamento do usuário final na recuperação temática da informação: um estudo com pós-graduandos da UNESP de Marília. Datagramazero, v. 6, n. 3, 2005.

GATTI, B. A. Grupo focal na pesquisa em ciências sociais e humanas. Brasília: Liber Livro, 2005. 75p.

GEORGE, C. et al. Scholarly use of information: graduate students' information seeking behavior. Information Research, v.11, n.4, p. 272, 2006.

GREEN, R. Locating sources in humanities scholarship: The efficacy of following bibliographic references. Library Quarterly, v. 70, n.3, p. 201-229, 2000.

MEADOWS. A comunicação científica. Brasília: Briquet Lemos Livros, 1999. 
MARCUSCHI, L. A. Análise da conversação. São Paulo: Ática, 1986.

ROMANOS DE TIRATEL, S. Accessing Information use by humanists and social scientists: a study at the Universidad de Buenos Aires, Argentina. The journal of academic librarianship, v. 26, n. 5, p. 346-354, sept. 2000.

SILVA, H. de C. O comportamento do usuário na busca e recuperação de informações: estudo longitudinal com pós-graduandos da UNESP de Marília. 2008. 41p. Relatório de pesquisa apresentado à UNESP e a FAPESP.

SILVA, H de C; OLIVEIRA, E. S. de. Aplicação da técnica de Grupo Focal para a caracterização do comportamento informacional de pós-graduandos da área de Educação.

In: ENCONTRO NACIONAL DE PESQUISA EM CIÊNCIA DA INFORMAÇÃO, 12, 2326 out. 2011, Brasília. Anais... Brasília: Thesaurus, 2011. Trabalho Oral. CD-Rom.

TODD, R. J. Adolescents of the information age: patterns of information seeking and use, and implications for information professionals. School Libraries Worldwide, v. 9, n. 2, p. 27-46, 2003.

WILSON, T. D. Human Information Behavior. Information Science Research, v. 3, n. 2, 2000 .

WILSON, T. D.; WALSH, C. Information behavior: an interdisciplinary perspective. Sheffield: University of Sheffield. Department of Information Studies, 1996. Disponível em: $<$ http://informationr.net/tdw/publ/infbehav/cont.html $>$. Acesso em: jan. 2012. 